The Knowledge Test Feedback Intervention (KTFI) increases knowledge level of spinal stenosis patients before operation-A randomized controlled follow-up trial

Kesanen, Jukka

2016-12

Kesanen , J , Leino-Kilpi , H , Lund, T, Montin , L , Puukka, P \& Valkeapaa , K 2016 , ' The Knowledge Test Feedback Intervention (KTFI) increases knowledge level of spinal stenosis patients before operation-A randomized controlled follow-up trial ' , Patient Education and Counseling , vol. 99 , no. 12 , pp. 1984-1991 . https://doi.org/10.1016/j.pec.2016.07.025

http://hdl.handle.net/10138/232109

https://doi.org/10.1016/j.pec.2016.07.025

publishedVersion

Downloaded from Helda, University of Helsinki institutional repository.

This is an electronic reprint of the original article.

This reprint may differ from the original in pagination and typographic detail.

Please cite the original version. 


\title{
The Knowledge Test Feedback Intervention (KTFI) increases knowledge level of spinal stenosis patients before operation-A randomized controlled follow-up trial is
}

\author{
Jukka Kesänen ${ }^{\mathrm{a}, \mathrm{b}, \mathrm{c}, *}$, Helena Leino-Kilpi ${ }^{\mathrm{a}, \mathrm{d}}$, Teija Lund ${ }^{\mathrm{e}}$, Liisa Montin ${ }^{\mathrm{b}}$, Pauli Puukka ${ }^{\mathrm{f}}$, \\ Kirsi Valkeapääa,g
}

a Department of Nursing Science, University of Turku, Turku, Finland

${ }^{\mathrm{b}}$ Orton Orthopaedic Hospital, Helsinki, Finland

${ }^{\mathrm{c}}$ Metropolia University of Applied Sciences, Helsinki, Finland

d Turku University Hospital, Turku, Finland

e Helsinki University Hospital, Jorvi Hospital, Espoo, Finland

${ }^{\mathrm{f}}$ National Institute for Health and Welfare, Turku, Finland

${ }^{\mathrm{g}}$ Lahti University of Applied Sciences, Lahti, Finland

\section{A R T I C L E I N F O}

\section{Article history:}

Received 8 November 2015

Received in revised form 29 April 2016

Accepted 14 July 2016

\section{Keywords:}

Empowering patient education

Empowering discourse

Knowledge test

Feedback

Spinal stenosis

Surgery

Randomized controlled trial

\begin{abstract}
A B S T R A C T
Objective: To assess the impact of a preoperative educational intervention on the knowledge level of patients with spinal stenosis.

Methods: One hundred spinal stenosis patients were randomized into a preoperative educational intervention group ( $I G, n=50$ ) or a control group ( $C G, n=50)$. All the patients received routine preoperative education. In addition, the IG went through an empowering telephone discourse based on a knowledge test performed before admission to hospital. Data on patients' knowledge level were collected at baseline (after the treatment decision), admission to hospital, discharge from hospital and at 3 and 6 months follow-up.

Results: At baseline, there was no difference in the knowledge level of the study groups. At admission, the knowledge level was significantly higher in five of six dimension of empowering knowledge in the IG compared to the CG. During follow-up, the knowledge level within the study groups remained stable. Conclusion: A preoperative KTFI significantly increased the patients' knowledge level in most dimensions of empowering knowledge.

Practice implication: KTFI is an effective method of preoperative education in patients with spinal stenosis.
\end{abstract}

(c) 2016 Elsevier Ireland Ltd. All rights reserved.

\section{Introduction}

Lumbar spinal stenosis (LSS, narrowing of the spinal canal) can cause considerable pain and disability, and can thus impair the quality of life of the aging population. [1-3]. Treatment of lumbar spinal stenosis is initially conservative (usually physical therapy and pain medication) unless absolute indications for surgery exist (e.g. progressive neurological deficits). With prolonged symptoms of significant pain and disability, surgical treatment is usually

\footnotetext{
is Trial registration: This trial is registered at Australian New Zealand Clinical Trials Registry (ANZCTR) ACTRN12611000417987.

* Corresponding author at: Department of Nursing Science, University of Turku, FIN-20014 Turun Yliopisto, Finland.

E-mail addresses: jpkesa@utu.fi, jukkakesanen@gmail.com (J. Kesänen).
}

considered [1]. LSS is the most common indication for spine surgery in older adults [1]. A shared decision-making process is recommended due to significant trade-offs between LSS treatment options, and differences in patient preferences and values [5]. For the patient to be able to actively participate in the decision-making process, a broad knowledge basis is required [4,6-8]. In general, knowledge expectations of surgical patients are high $[9,10]$ albeit rarely met in clinical practice [11,12]. Thus, effective patient education methods are needed [11]. Furthermore, these education methods need to be individually tailored, as learning styles and strategies differ from patient to patient. It is the responsibility of health care professionals to ensure that patients' knowledge level is sufficient for undergoing the treatment proper [13].

In previous literature, patient education methods tailored for spine surgery patients have concentrated on decision-making 
regarding treatment (an interactive video and booklet [14], an information sheet [15] and an evidence-based video [16]), anxiety related to the operation (web-based information program [17]), and postoperative rehabilitation (evidence-based booklet [18]). The impact of preoperative patient education with the framework of the entire surgical pathway has not been studied to date in spine surgery patients.

When designing our preoperative educational intervention, we used the concept of empowering patient education (EPE) which aims at recognising and improving the patients' ability to make informed choices and better control their health problem, i.e. to become empowered [19-21] through active and equal participation $[22,23]$. In this empowering process, knowledge is an essential element $[24,25]$ consisting the following six dimensions: the biophysiological (e.g. aetiology, symptoms, treatment, complications), functional (e.g. mobility, rehabilitation, rest, nutrition), social (patient unions, family and work), experiential (emotions, attitude), ethical (patient rights, participation in decision-making and confidentiality), and financial (costs and social benefits). For surgical patients to be able to prepare for surgery, they need knowledge on all these dimensions $[9,11,20,26]$. Moreover, to be able to support the patients' empowerment, health care professionals need information on patients' existing knowledge level [19,27-29].

Different EPE methods have proven effective in diverse patient groups. In surgical patients, they have not only increased the knowledge level [30], but also resulted in decreased preoperative anxiety [31-34], faster recovery, lower incidence of complications, improved quality of communication between patients and health care professionals [34], higher postoperative quality of life [7] and better certainty of care-related issues and a more positive learning experience [35]. In addition, EPE has been connected to the quality of nursing care [36].

In the present study, the preoperative Knowledge Test Feedback Intervention (KTFI) consisted of an empowering telephone discourse based on a specially designed knowledge test. Feedback plays a fundamental role in empowering discourse, as it provides the patients with an understanding of their knowledge level, and demonstrates the existing knowledge gaps, thus directing future learning [35,37]. Moreover, feedback supports the educator in tailoring the teaching for the individual patient [38].

In an empowering discourse, both the educator and the patient have an essential role in bringing their own expertise to the discourse. The empowering discourse consist of three phases: (1) initiation, (2) progression, and (3) conclusion. In the initiation phase, the aim is to create a positive and respectful atmosphere by equal participation and mutual understanding of the goal of the discourse. The educator's role is essential as an initiator. The progression phase starts with assessment of patient's knowledge base, skills and expectations. In the progression phase, the educator invites the patient to participate in decision-making with own interpretations of the issues in question. In the conclusion phase, the initial goals are revised and the results are summarised. [39,40].

We designed a randomized controlled trial to assess the impact of the Knowledge Test Feedback Intervention (KTFI) on patients' knowledge level; the comparison was between an intervention group (IG) and a control group (CG). Further, we wanted to evaluate the feasibility of the KTFI. Our ultimate goal was to improve the preoperative education of spine surgery patients.

The research questions were as follows:

(1) What was the patient's knowledge level at different stages of the surgical process?

(2) Was there a difference in the knowledge level between the study groups?
(3) Was the educational intervention feasible from the patients' perspective?

We set the following hypothesis:

The KTFI increases the patient's knowledge level compared to routine preoperative education.

\section{Methods}

\subsection{Design and settings}

The present study was a randomized controlled double-blinded intervention trial with a six-month follow-up (Fig. 1). The data collection was conducted from April 2011 to January 2013 in the spine department of an orthopaedic hospital with approximately 400 spinal operations per year.

\subsection{Participants and recruitment}

Adult patients undergoing surgery for spinal stenosis were eligible to participate in the study. Inclusion criteria were: willingness to participate, age 18 or older, sufficient understanding of the Finnish language, access to a telephone. Exclusion criteria were: spine surgery for some other indication, time from decision to surgery shorter than 4 weeks. This time limit was chosen to allow us enough time to arrange the intervention. The research nurse or the principal investigator recruited eligible patients either at the outpatient clinic or by telephone after the treatment decision. From a total of 132 eligible patients invited, one hundred were randomized into the intervention ( $I G, n=50$ ) or the control (CG, $\mathrm{n}=50$ ) group. 87 patients completed the 6-month follow-up (47 in the IG and 40 in the CG). The reasons for refusals and dropouts are presented in Fig. 1.

\subsection{Sample size}

The present study reports the results of one part of a larger project on the outcomes of preoperative education of spinal stenosis patients. As the KNOWBACK Test was specifically developed for this study, the sample size calculation could not be based on it, but on Spielberger's State-Trait Anxiety Inventory for adults (STAI) [41], the primary outcome of the clinical follow-up of the study project. With 100 participants the study has an $80 \%$ power to detect a difference of 3 points in anxiety between the two groups $(p=0.05)$, allowing a $15 \%$ dropout rate. The power calculation was based on the two group $t$-test.

\subsection{Randomization}

To ensure balance of participant characteristics between the study groups the minimization method of randomization [42] was based on educational level, age and gender. The research nurse conducted the randomization using the MINIM software (www. sghms.ac.uk/depts/phs/guide/randser.htm) and allocated patients into the two study groups after informed consent. The study group allocation was then saved to password protected research chart.

\subsection{Blinding}

All health care professionals involved in the care of the patients were blinded to the study group allocation. In order to blind the patients, the study group descriptions were intentionally cursory; the patients were aware of the general purpose of the study, but not of the group allocation [43]. Both groups received a telephone call from the research nurse before the operation: in the IG, an empowering discourse based on a knowledge test was conducted, 


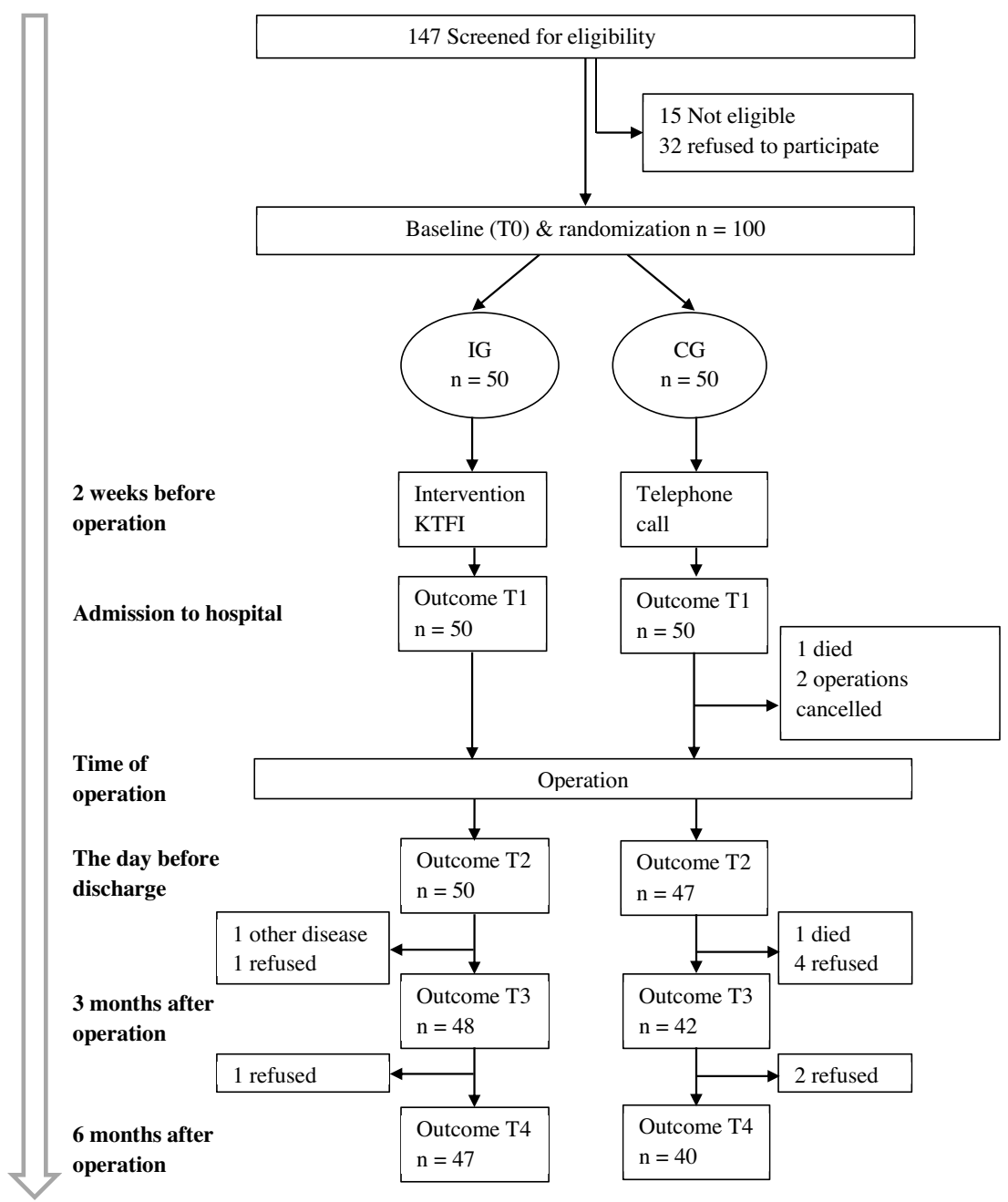

Fig. 1. Study design and participant flow.

IG = Intervention Group, GC= Control Group, T0-4 = Measurement point 0-4

and in the CG, a general discussion concentrated on the patient's health history (diseases, allergies, medication, previous operations and hospital experiences). Possible contamination during the study period could not be controlled, e.g. the patients could use different information sources at any time during the follow-up.

\subsection{Preoperative routine education}

All the patients received the routine preoperative education according to the hospital guidelines. The face-to-face discussion with the surgeon dealt with general information about spinal stenosis, available treatment options, and different aspects of surgical treatment (e.g. complications and surgical outcomes). Written material and a face-to-face discussion with a nurse provided the patients with advice on how to prepare for the surgery. Any concerns the patients might have had were clarified during these discussions. An anaesthesiologist and a physiotherapist met the patients when they were hospitalized for surgery.

\subsection{Intervention}

In addition to the routine preoperative patient education, the patients of the IG underwent the Knowledge Test Feedback Intervention (KTFI, see Fig. 2) consisting of an empowering telephone discourse based on the patient's existing knowledge.
The KTFI was developed specifically for the present study using existing literature $[35,39,40,44]$, an expert panel (10 nursing science researchers) and a pilot test with two patients (data included in the results). The intervention occurred on an average 9 days before the operation (range 3-35 days). The goal of the intervention was to increase the patients' knowledge on preparation for and recovery from spinal stenosis surgery.

The structure of the empowering discourse [39,40] was modified for the present study. At baseline (after decision of surgery) the patient completed a test evaluating his/her knowledge level on issues around the planned surgical treatment (KNOWBACK Test, see below). A copy of the corrected test was sent to the patient before the empowering telephone discourse. During the progression phase of the discourseall right answers were noted and wrong answers were corrected. The patient regulated the depth of the discourse by expressing his/her willingness to discuss the different issues either on a general or on a deeper and more detailed level. The nurse enabled this by open-ended questions and active listening. The mean duration of the discourse was $21 \mathrm{~min}$ (range 8-65 min).

\subsection{Measurements}

The patients' knowledge level was the primary outcome of this part of the study project. The measurements were scheduled at 


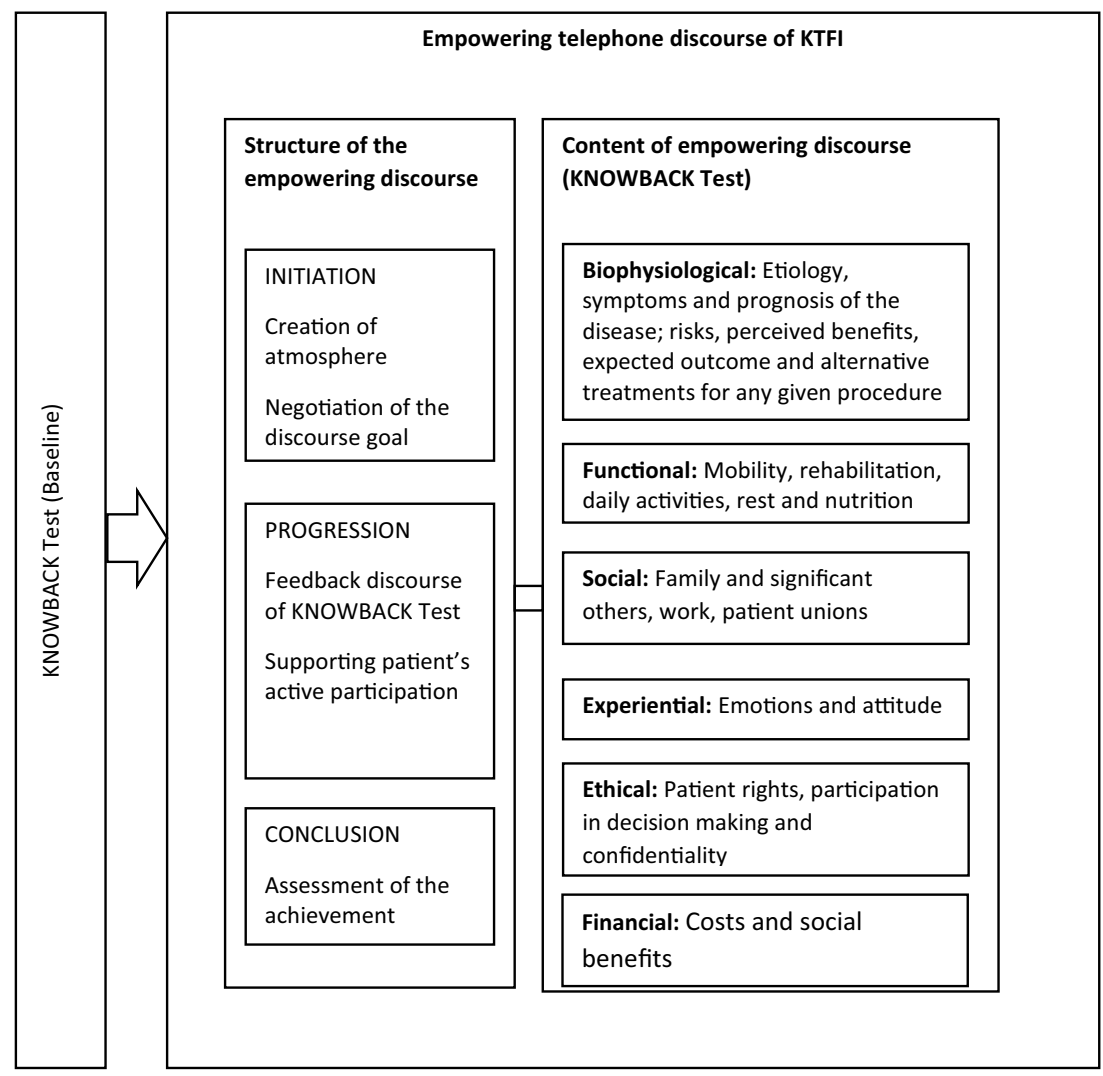

Fig. 2. The structure of Knowledge Test Feedback Intervention $[20,35,39,40]$.

baseline (T0), at admission to hospital (T1), on the day before discharge (T2), and at three (T3) and six months (T4) after the surgery (Fig. 1). Patients in both study groups completed the data collection questionnaires at home at T0, T3 and T4; at T1 and T2 they completed the questionnaires at the hospital ward. At T1 we also assessed the feasibility of the KNOWBACK Test from the patients' perspective. The data collection was conducted by the research secretary blinded to the study group allocation.

\subsubsection{KNOWBACK test}

The theoretical bases of the KNOWBACK Test is the sixdimensional empowering knowledge [11,20] within the framework of the surgical pathway of spinal stenosis patients, i.e. knowledge related to the pre-, peri- and postoperative phases of surgical process. A first draft of the test ( 28 items) was based on the existing literature and on the educational material of the hospital. In the second phase, an expert panel ( 3 nurses, 1 physiotherapist, 1 clinical nurse specialist) assessed the adequacy and clarity of the test items based on content validity index (CVI). The expert panel negotiated until they achieved CVI 0.8 [45]. One item concerning the possibility of waking up during anaesthesia was left out because it was considered too frightening. Three additional items were reworded for clarity. In the third phase, a patient panel with
10 spine surgery patients assessed the adequacy and clarity of the test. They suggested no additional modifications.

At this point, the KNOWBACK Test consisted of a total of 27 items and 6 subscales according to the dimensions of empowering knowledge [11,20] (Fig. 2). Possible responses to each individual item were "true", "false" or "do not know" (examples in Table 1). The total test score (range $0-27$ ) was calculated by giving a score of 1 to a correct response, and a score of 0 to an incorrect, missing or "do not know" response. Thus, the scores of correct answers constituted the patient's knowledge level. The scores were calculated for the whole KNOWBACK Test and for each subscale separately.

Finally, 50 spine surgery patients who were not part of the present study, completed the KNOWBACK Test before their scheduled surgery. In this pilot study, the percentage of correct answers on an item level ranged from 1 to $91 \%$, with SD of the different items ranging between 12 and 50\%.

We used the Back Pain Knowledge test [14] to measure the criterion validity of the bio-physiological subscale of the KNOWBACK Test. The Back Pain Knowledge test is a 17-item questionnaire concentrating on the pathology, treatment options, and outcomes of spine surgery and conservative care. It has been validated in low back pain patients who were potential candidates for surgical

Table 1

Three examples of the items of the KNOWBACK Test.

\begin{tabular}{|c|c|c|c|}
\hline \multicolumn{4}{|l|}{ KNOWBACK Test } \\
\hline Bed rest after spinal surgery enhances the recovery. & true & false & I don't know \\
\hline Smoking enhances the healing of the operation wound. & true & false & I don't know \\
\hline Patient's significant others can read the patient's health history whenever they wish. & true & false & I don't know \\
\hline
\end{tabular}


treatment [14]. In the present study sample, a statistically significant correlation ranging from 0.37 to 0.63 ( $\mathrm{p}<0.0001-$ 0.008 ) was established between the bio-physiological subscale of the KNOWBACK Test and the Back Pain Knowledge Test.

\subsubsection{Patients' evaluation of the feasibility of the education}

At $\mathrm{T} 1$ the patients assessed the feasibility (clarity, intelligibility, adequacy) of the KTFI using a previously developed instrument modified for the purposes of this study [46]. The Cronbach's alpha coefficient of the instrument was 0.85 .

\subsubsection{Demographic information}

Demographic and health history data collected were as follows: gender, age, civil status, basic education, employment status, health care profession, duration of the hospitalization, and previous operations.

\subsection{Analysis}

The participants' characteristics were presented as frequencies and percentages or means and SDs. The differences between study groups were analysed with $t$-test for normally distributed variables or with Wilcoxon two-sample test if the variables were not normally distributed. Chi-square or Fisher's test were applied for categorical variables. The knowledge level indicated by the KNOWBACK Test was analysed with two way repeated measures analysis of variance (ANOVA) with the group (IG, CG) as a betweensubject factor, and time point (T0, T1, T2, T3, T4) as a within-subject factor. As all group*time interactions were significant, the groups were additionally analysed with repeated measures ANOVA separately. All pairwise comparisons were performed using Tukey-Kramer adjustment. Internal consistency of the KNOWBACK Test was evaluated using Cronbach's alpha coefficient. For criterion validity Spearman correlations between KNOWBACK Test and Back Pain Knowledge Test were calculated. The data were analysed using SAS 9.3 (SAS Institute Inc., Cary, NC, USA). P-values of less than 0.05 were chosen as statistically significant.

\subsection{Ethical considerations}

The ethical approval was obtained from the Ethics Committee of the Hospital District of Helsinki and Uusimaa (280/13/03/02/2010). Research permission from the hospital and all relevant permissions from the copyright holders of the different instruments were obtained. Patients gave their written informed consent after having received verbal and written information of the study. The study was carried out in accordance with the Declaration of Helsinki and Responsible Conduct of Research [47].

\section{Results}

\subsection{Participant characteristics}

There were no statistically significant differences between the study groups at baseline. In both groups, the majority of patients were female, retired, age 60 years or older. The average hospital stay was 7 days. Almost all patients had earlier experiences of surgical procedures. (Table 2).

\subsection{Knowledge level during follow-up}

In the IG, the total knowledge level was at baseline (T0) 13.4 (SD 3.9; scale 0-27; range 4-21), at admission (T1) 21.6 (SD 3.5; range 8-25), at discharge (T2) 21.4 (SD 3.4; range 10-26), at three months (T3) 21.2 (SD 4.6; range 11-27) and at six months (T4) 20.3 (SD 4.5;
Table 2

Participant characteristics at baseline, $p$-values describe the between group differences.

\begin{tabular}{|c|c|c|c|}
\hline & IG n (\%) & CG n (\%) & p-value \\
\hline \multicolumn{4}{|l|}{ Gender } \\
\hline Male & $17(34)$ & $19(38)$ & 0.677 \\
\hline Female & $33(66)$ & $31(62)$ & \\
\hline \multicolumn{4}{|l|}{ Age } \\
\hline Mean age years (SD) & $61.9(12.5)$ & $63.0(11.9)$ & 0.654 \\
\hline \multicolumn{4}{|l|}{ Civil Status } \\
\hline Living alone & $12(24)$ & $15(30)$ & 0.091 \\
\hline Living with someone & $38(76)$ & $35(70)$ & \\
\hline \multicolumn{4}{|l|}{ Basic education } \\
\hline Six years or less & $16(32)$ & $16(32)$ & \\
\hline Nine years & $21(42)$ & $23(46)$ & 0.879 \\
\hline Twelve years & $13(26)$ & $11(22)$ & \\
\hline \multicolumn{4}{|l|}{ Employment status } \\
\hline Employed & $15(30)$ & $13(26)$ & \\
\hline Retired & $29(58)$ & $35(70)$ & 0.259 \\
\hline Other & $6(12)$ & $2(4)$ & \\
\hline \multicolumn{4}{|l|}{ Work in health care } \\
\hline Yes & $10(20)$ & $13(26)$ & 0.476 \\
\hline No & $40(80)$ & $37(74)$ & \\
\hline \multicolumn{4}{|l|}{ Hospital stay } \\
\hline Mean days (SD) & $7.1(2.4)$ & $7.5(2.6)$ & 0.446 \\
\hline Range days & $3-16$ & $3-15$ & \\
\hline \multicolumn{4}{|c|}{ Previous spinal operation(s) } \\
\hline Yes & $17(34)$ & $16(33)$ & 0.986 \\
\hline \multicolumn{4}{|c|}{ Other previous operations } \\
\hline Yes & $39(80)$ & $45(92)$ & 0.100 \\
\hline
\end{tabular}

IG = Intervention Group.

$\mathrm{CG}=$ Control Group.

Significant $\mathrm{p}<0.05$.

range 11-26). The knowledge level of the IG increased statistically significantly by 8.2 scores (95\% CI 6.6-9.7, p $<0.0001$ ) after the intervention (T1), and remained stable throughout the follow-up (Table 3).

In the CG, the total knowledge level at the baseline was 13.9 (SD 4.5; range 3-21) and reached the highest level of 15.4 (SD 4.1; range 3-22) at discharge (T2). During the hospitalization (between $\mathrm{T} 1$ and T2) there was a minor but non-significant increase of 2.2 scores $(95 \% \mathrm{CI}-3.6$ to $7.9, \mathrm{p}=0.0619)$. The knowledge level remained stable throughout the follow-up (Table 3 ).

In the subscales of the KNOWBACK Test at baseline, the highest knowledge level of 2.5 scores (SD 0.7, scale 0-3) was on the experiential subscale in both study groups, and the lowest knowledge level of 0.9 scores (SD 0.9, scale $0-3$ ) in the IG in the ethical dimension.

In the IG, there was a statistically significant knowledge level increase in all other subscales ( $\mathrm{p}_{\text {time }}<0.0001$ ) but the experiential dimension ( $p_{\text {time }}=0.2968$ ). In the $C G$, a statistically significant knowledge increase was noted in bio-physiological $\left(\mathrm{p}_{\text {time }}=\right.$ $0.0003)$, functional $\left(p_{\text {time }}<0.0001\right)$ and ethical $\left(p_{\text {time }}=0.0267\right)$ subscales (Table 3 ).

\subsection{Between group differences in knowledge level}

There was no statistically significant difference $(-0.5$ score, $95 \%$ $\mathrm{CI}-2.2$ to $1.1, \mathrm{p}=0.5363$ ) between the study groups at baseline (T0) in the total knowledge level or in any of the subscales (Table 3 ). The 
Table 3

Knowledge level on the total scale and the subscales of the KNOWBACK Test (number of correct answers).

\begin{tabular}{|c|c|c|c|c|c|c|c|c|c|c|c|c|}
\hline $\begin{array}{l}\text { Scales } \\
\text { (score) }\end{array}$ & Group & $\begin{array}{l}\text { T0 } \\
\text { mean (SD) }\end{array}$ & $\mathrm{n}$ & $\begin{array}{l}\mathrm{T} 1 \\
\text { mean }(\mathrm{SD})\end{array}$ & $\mathrm{n}$ & $\begin{array}{l}\mathrm{T} 2 \\
\text { mean }(\mathrm{SD})\end{array}$ & $\mathrm{n}$ & $\begin{array}{l}\text { T3 } \\
\text { mean (SD) }\end{array}$ & $\mathrm{n}$ & $\begin{array}{l}\text { T4 } \\
\text { mean (SD) }\end{array}$ & $\mathrm{n}$ & ptime \\
\hline $\begin{array}{l}\text { Total scale } \\
(0-27)\end{array}$ & $\begin{array}{l}\text { Intervention } \\
\text { Control } \\
\text { pgroup } \\
\text { CI 95\% }\end{array}$ & $\begin{array}{l}13.4(3.9) \\
13.9(4.5) \\
0.5363 \\
-2.2 \text { to } 1.1\end{array}$ & $\begin{array}{l}50 \\
50\end{array}$ & $\begin{array}{l}21.6(3.5) \\
13.9(4.1) \\
<0.0001 \\
6.2-9.2\end{array}$ & $\begin{array}{l}50 \\
50\end{array}$ & $\begin{array}{l}21.4(3.4) \\
15.4(4.1) \\
<0.0001 \\
4.5-7.5\end{array}$ & $\begin{array}{l}49 \\
46\end{array}$ & $\begin{array}{l}21.2(4.6) \\
15.2(4.2) \\
<0.0001 \\
4.1-7.9\end{array}$ & $\begin{array}{l}45 \\
40\end{array}$ & $\begin{array}{l}20.3(4.5) \\
14.6(3.9) \\
<0.0001 \\
3.8-7.5\end{array}$ & $\begin{array}{l}44 \\
37\end{array}$ & $\begin{array}{l}<0.0001 \\
0.0005\end{array}$ \\
\hline $\begin{array}{l}\text { Subscales } \\
\text { Bio-physiogical } \\
(0-9)\end{array}$ & $\begin{array}{l}\text { Intervention } \\
\text { Control } \\
\text { pgroup }_{\text {CI 95\% }}\end{array}$ & $\begin{array}{l}3.9(1.6) \\
4.0(1.8) \\
1.0 \\
-1.2 \text { to } 1.0\end{array}$ & $\begin{array}{l}50 \\
50\end{array}$ & $\begin{array}{l}7.2(2.0) \\
4.1(1.8) \\
<0.0001 \\
2.0-4.2\end{array}$ & $\begin{array}{l}50 \\
50\end{array}$ & $\begin{array}{l}7.1(1.8) \\
4.6(1.6) \\
<0.0001 \\
1.3-3.6\end{array}$ & $\begin{array}{l}49 \\
46\end{array}$ & $\begin{array}{l}6.6(1.9) \\
4.6(1.8) \\
<0.0001 \\
0.9-3.2\end{array}$ & $\begin{array}{l}45 \\
40\end{array}$ & $\begin{array}{l}5.8(1.8) \\
4.0(1.6) \\
<0.0001 \\
0.7-3.1\end{array}$ & $\begin{array}{l}44 \\
37\end{array}$ & $\begin{array}{l}<0.0001 \\
0.0003\end{array}$ \\
\hline $\begin{array}{l}\text { Functional } \\
(0-6)\end{array}$ & $\begin{array}{l}\text { Intervention } \\
\text { Control } \\
\text { pgroup } \\
\text { CI 95\% }\end{array}$ & $\begin{array}{l}3.3(1.2) \\
3.0(1.4) \\
0.9976 \\
-0.6 \text { to } 1.0\end{array}$ & $\begin{array}{l}50 \\
50\end{array}$ & $\begin{array}{l}5.2(0.9) \\
3.2(1.5) \\
<0.0001 \\
1.3-2.9\end{array}$ & $\begin{array}{l}50 \\
50\end{array}$ & $\begin{array}{l}5.0(1.2) \\
4.0(1.5) \\
0.0060 \\
0.2-1.8\end{array}$ & $\begin{array}{l}49 \\
46\end{array}$ & $\begin{array}{l}5.0(1.1) \\
4.2(1.4) \\
0.0380 \\
0.0-1.7\end{array}$ & $\begin{array}{l}45 \\
40\end{array}$ & $\begin{array}{l}5.1(1.1) \\
4.2(1.4) \\
0.0166 \\
0.1-1.8\end{array}$ & $\begin{array}{l}44 \\
37\end{array}$ & $\begin{array}{l}<0.0001 \\
<0.0001\end{array}$ \\
\hline $\begin{array}{l}\text { Social } \\
(0-3)\end{array}$ & $\begin{array}{l}\text { Intervention } \\
\text { Control } \\
\text { p group } \\
\text { CI95\% }\end{array}$ & $\begin{array}{l}1.2(1.0) \\
1.3(0.7) \\
1.0 \\
-0.5 \text { to } 0.5\end{array}$ & $\begin{array}{l}50 \\
50\end{array}$ & $\begin{array}{l}2.4(0.8) \\
1.1(1.0) \\
<0.0001 \\
0.8-1.9\end{array}$ & $\begin{array}{l}50 \\
50\end{array}$ & $\begin{array}{l}2.6(0.7) \\
1.2(0.8) \\
<0.0001 \\
0.9-2.0\end{array}$ & $\begin{array}{l}49 \\
46\end{array}$ & $\begin{array}{l}2.5(0.8) \\
1.4(1.0) \\
<0.0001 \\
0.5-1.6\end{array}$ & $\begin{array}{l}45 \\
40\end{array}$ & $\begin{array}{l}2.2(0.9) \\
1.3(0.9) \\
<0.0001 \\
0.3-1.5\end{array}$ & $\begin{array}{l}44 \\
37\end{array}$ & $\begin{array}{l}<0.0001 \\
0.2082\end{array}$ \\
\hline $\begin{array}{l}\text { Experiential } \\
(0-3)\end{array}$ & $\begin{array}{l}\text { Intervention } \\
\text { Control } \\
\text { pgroup }_{\text {CI }} \\
\text { CI 95\% }\end{array}$ & $\begin{array}{l}2.5(0.7) \\
2.5(0.7) \\
1.0 \\
-0.4 \text { to } 0.3\end{array}$ & $\begin{array}{l}50 \\
50\end{array}$ & $\begin{array}{l}2.3(0.5) \\
2.7(0.5) \\
0.0094 \\
-0.7 \text { to }-0.1\end{array}$ & $\begin{array}{l}50 \\
50\end{array}$ & $\begin{array}{l}2.4(0.6) \\
2.7(0.4) \\
0.0325 \\
-0.7 \text { to }-0.0\end{array}$ & $\begin{array}{l}49 \\
46\end{array}$ & $\begin{array}{l}2.5(0.5) \\
2.0(0.4) \\
0.0017 \\
0.1-0.9\end{array}$ & $\begin{array}{l}45 \\
40\end{array}$ & $\begin{array}{l}2.5(0.6) \\
2.1(0.4) \\
0.0658 \\
-0.0 \text { to } 0.8\end{array}$ & $\begin{array}{l}44 \\
37\end{array}$ & $\begin{array}{l}0.2968 \\
<0.0001\end{array}$ \\
\hline $\begin{array}{l}\text { Ethical } \\
(0-3)\end{array}$ & $\begin{array}{l}\text { Intervention } \\
\text { Control } \\
\text { p group }_{\text {CI 95\% }}\end{array}$ & $\begin{array}{l}0.9(0.9) \\
1.2(1.1) \\
0.9524 \\
-0.8 \text { to } 0.3\end{array}$ & $\begin{array}{l}50 \\
50\end{array}$ & $\begin{array}{l}2.6(0.8) \\
1.2(1.0) \\
<0.0001 \\
0.8-2.0\end{array}$ & $\begin{array}{l}50 \\
50\end{array}$ & $\begin{array}{l}2.5(0.8) \\
1.2(1.0) \\
<0.0001 \\
0.7-1.9\end{array}$ & $\begin{array}{l}49 \\
46\end{array}$ & $\begin{array}{l}2.3(0.9) \\
1.4(0.9) \\
<0.0001 \\
0.3-1.6\end{array}$ & $\begin{array}{l}45 \\
40\end{array}$ & $\begin{array}{l}2.3(0.9) \\
1.4(0.9) \\
0.0030 \\
0.2-1.4\end{array}$ & $\begin{array}{l}44 \\
37\end{array}$ & $\begin{array}{l}<0.0001 \\
0.0267\end{array}$ \\
\hline $\begin{array}{l}\text { Financial } \\
(0-3)\end{array}$ & $\begin{array}{l}\text { Intervention } \\
\text { Control } \\
\text { Pgroup } \\
\text { CI 95\% }\end{array}$ & $\begin{array}{l}1.5(0.9) \\
1.9(1.2) \\
0.5840 \\
-0.9 \text { to } 0.2\end{array}$ & $\begin{array}{l}50 \\
50\end{array}$ & $\begin{array}{l}1.9(0.5) \\
1.7(0.9) \\
0.9180 \\
-0.3 \text { to } 0.8\end{array}$ & $\begin{array}{l}50 \\
50\end{array}$ & $\begin{array}{l}1.9(0.6) \\
1.8(1.0) \\
0.9975 \\
-0.3 \text { to } 0.7\end{array}$ & $\begin{array}{l}49 \\
46\end{array}$ & $\begin{array}{l}2.4(0.8) \\
1.7(0.9) \\
0.0018 \\
0.2-1.3\end{array}$ & $\begin{array}{l}45 \\
40\end{array}$ & $\begin{array}{l}2.5(0.7) \\
1.5(0.8) \\
<0.0001 \\
0.3-1.5\end{array}$ & $\begin{array}{l}44 \\
37\end{array}$ & $\begin{array}{l}<0.0001 \\
0.2251\end{array}$ \\
\hline
\end{tabular}

All interactions between the groups and time were significant $(\mathrm{p}<0.0001)$. Significant $\mathrm{p}<0.05$.

difference of the total knowledge level between the study groups was statistically significant $(\mathrm{p}<0.0001)$ after the intervention at all measurement points (T1-T4).

Within the subscales of the KNOWBACK Test, there was a statistically significant difference between the IG and the CG in bio-physiological, functional, social and ethical subscales at all measurement points after the intervention (T1-T4). In the experiential subscale, the CG scored statically significantly higher than the IG at T1-T2 and vice versa at T3-T4 (Table 3).

\subsection{Patients' evaluation of the feasibility of the education}

The sum score of the clarity, intelligibility and adequacy of the KTFI in IG was 4.5 (SD 0.6, scale 0-5). No correlation existed between the perceived feasibility of the intervention and the measured knowledge level.

\section{Discussion and conclusion}

\subsection{Discussion}

KTFI proved to be effective in increasing the knowledge level of the patients, which is in line with previous studies on education of spine surgery patients $[14,17]$. The knowledge level measured with the KNOWBACK Test was approximately $50 \%$ of the maximum at the baseline in both study groups, and in the IG it increased by $29 \%$ points after the KTFI while there was no change in the CG. In the IG, all dimensions of empowering knowledge increased except the experiential which was at high level already at baseline. This is most probably due to the fact that most patients had experiences of surgical treatment. The change in knowledge level proved stable throughout the six-month follow-up.

In the CG, there was a minor, but statistically not significant increase in the total knowledge level during the hospitalization. This may be due to an increase in the bio-physiological and functional dimensions, which are covered by the routine patient education [11]. The increase of knowledge level in the biophysiological and functional dimensions may be beneficial in the empowering process, as the knowledge expectations of orthopaedic patients have been shown highest in these two dimensions $[9,11,30]$. However, from the standpoint of empowerment, in order to ensure sufficient knowledge of the whole surgical pathway, patients need to be educated on all dimensions of empowering knowledge [11].

The patients assessed the feasibility (clarity, intelligibility, adequacy) of the KTFI very high, making it a potentially usable patient education method from the perspective of patients [48]. On the other hand, the high rating does not give any suggestions for future development of the KTFI [49]. The high feasibility rating may be due to the individual character of the intervention which was based on the patients' actual needs. We believe that such lowtechnology patient education methods are needed; many older people may lack the access to information technology [50] and patients vary in how they learn [51].

Although our educational intervention required relatively few resources and was easy to conduct, it proved effective in increasing the patients' knowledge level regarding in all aspects of their surgical treatment. Previous literature suggests that this may lead 
to positive clinical outcomes such as decreased preoperative anxiety [31-34], faster recovery, lower incidence of complications [34], and higher postoperative quality of life [7]. However, the clinical importance of increased knowledge needs further study. Moreover, based on the present data, there is no way of knowing whether a threshold level of knowledge exists that would be beneficial for the surgery.

Our study has several strengths. According to our knowledge, this is the first randomized controlled trial on spinal stenosis surgery patients' preoperative education covering the whole surgical pathway from preoperative phase to postoperative follow-up. All eligible patients were asked to participate in the study, and the study groups were comparable in baseline characteristics. The patients and caregivers were blinded, and the dropout rate (13\%) was lower than the sample size calculation (15\%) allowed.

The content validity of the KNOWBACK Test was based on previous literature, an expert and patient panel and it was piloted in a group of spine surgery patients. A moderate to strong correlation between the KNOWBACK Test and the Back Pain Knowledge Test was established, which strengthened the validity of the KNOWBACK Test [52]. The reliability of the KNOWBACK Test was assessed using Cronbach's alpha coefficient for the total scale. The alpha was 0.6 in the T0 measure of the IG, and in all other measure points the alpha ranged from 0.7 to 0.8 which can be considered acceptable for a newly developed instrument [52]. However, the KNOWBACK Test needs further development especially regarding the experiential subscale.

The usability of the KTFI was based on previous literature, an expert panel, and a pilot test with two patients. One nurse trained in the KTFI conducted all the interventions to minimize the possibility of variation. Although the process itself seemed to work well there was variation in the time between the intervention and the operation (range 335 days), mainly due to a short waiting list with frequent changes. Thus, the results of the study cannot be used to determine the optimal timing for preoperative patient education.

Our study has some limitations. The same test (KNOWBACK Test) was used first to measure the baseline knowledge level and then repeatedly as an outcome measure, which might have increased the risk of recall bias. A minimum period of two weeks has been recommended between the retake of a test to avoid remembering the answers rather than understanding the issues [52]. As our study was conducted in a clinical setting, we could not control the time interval between the test and the re-test (T0 and T1). Nevertheless, the knowledge level remained stable in both study groups during follow-up, which would suggest that the variation in the time interval between the intervention and T1 may not have affected the outcome.

Patient contamination (information from sources outside the study framework) could not be controlled as the patients had the corrected KNOWBACK Test at their disposal, and may have consulted other information sources for further learning. However, this is the basic idea behind EPE; individual information searching is encouraged, and the KNOWBACK Test may have acted as an educational checklist.

Possible bias arises from the fact that our patients were slightly younger than patients with lumbar spinal stenosis in previous studies [16,53]. In our patient group, female gender was overrepresented due to higher prevalence of lumbar spinal stenosis in females compared to males [3]. The education level of our patients was similar to the average national population in the same age group [54]. In conclusion, our patient group can be regarded as representative, and thus the results can be generalized to surgical patients with LSS.

\subsection{Conclusion}

In a group of spinal stenosis patients scheduled for surgery, the KTFI was effective and feasible in increasing the bio-physiological, functional, social, ethical, and financial dimensions of empowering knowledge.

\subsection{Practical implications}

Our results suggest that KTFI is an easily implemented and feasible preoperative education intervention for spinal stenosis patients. The KNOWBACK Test may prove beneficial as a checklist in patient education. In nursing management, it can be used to measure the quality of preoperative patient education.

\section{Authors' contributions}

Authors contributions was as follows: (1) the conception and design of the study (JK, HL-K, TL, LM, PP, KV) acquisition of data (JK), analysis (PP) and interpretation of data (JK, HL-K, TL, LM, PP, KV), (2) drafting the article (JK, TL, PP) and revising it critically for important intellectual content (JK, HL-K, TL, LM, PP, KV), (3) final approval of the version to be submitted (JK, HL-K, TL, LM, PP, KV).

\section{Funding}

This study was supported by the Finnish Nurses Association, The Finnish Association of Nursing Research, The Research Association of Nurses, and the state research funding granted by the Invalid Foundation and the Hospital district of South-Western Finland. The funding sources had no involvement in the study design, data collection, analysis and interpretation, writing the report, or publication process.

\section{Conflict of interest statement}

The authors have no conflict of interest to declare.

\section{Acknowledgement}

We gratefully acknowledge the work of our research nurse Riikka Ruuskanen and research secretary Ella Haaranen.

\section{References}

[1] R.A. Deyo, Treatment of lumbar spinal stenosis: a balancing act, Spine J. 10 (2010) 625-627, doi:http://dx.doi.org/10.1016/j.spinee.2010.05.006.

[2] M.C. Battié, C.A. Jones, D.P. Schopflocher, R.W. Hu, Health-related quality of life and comorbidities associated with lumbar spinal stenosis, Spine J. 12 (2012) 189-195, doi:http://dx.doi.org/10.1016/j.spinee.2011.11.009.

[3] K. Otani, S. Kikuchi, S. Yabuki, T. Igarashi, T. Nikaido, K. Watanabe, et al., Lumbar spinal stenosis has a negative impact on quality of life compared with other comorbidities: an epidemiological cross-sectional study of 1862 communitydwelling individuals, Sci. World J. 2013 (2013), doi:http://dx.doi.org/10.1155/ 2013/590652 Article ID 590652 .

[4] M.F. Kurd, J.D. Lurie, W. Zhao, T. Tosteson, A.S. Hilibrand, J. Rihn, et al., Predictors of treatment choice in lumbar spinal stenosis: a spine patient outcomes research trial study, Spine (Phila. Pa. 1976) 37 (2012) 1702-1707, doi http://dx.doi.org/10.1097/BRS.0b013e3182541955.

[5] S. Genevay, S.J. Atlas, Lumbar spinal stenosis, Best Pract. Res. Clin. Rheumatol 24 (2010) 253-265, doi:http://dx.doi.org/10.1016/j.berh.2009.11.001.

[6] K. Roszell, D. Sandella, A.J. Haig, K.S.J. Yamakawa, Spinal stenosis: factors that influence patients' decision to undergo surgery, J. Spinal Disord. Tech. (2013), doi:http://dx.doi.org/10.1097/BSD.0b013e31829e1514 in press.

[7] J. Zieren, C. Menenakos, J.M. Mueller, Does an informative video before inguinal hernia surgical repair influence postoperative quality of life? Results of a prospective randomized study, Qual. Life Res. 16 (2007) 725-729, doi: http://dx.doi.org/10.1007/s11136-007-9171-y.

[8] G.M. Ghobrial, A. Mehdi, M. Maltenfort, A.D. Sharan, J.S. Harrop, Variability of patient spine education by Internet search engine, Clin. Neurol. Neurosurg. 118 (2014) 59-64, doi:http://dx.doi.org/10.1016/j.clineuro.2013.12.013. 
[9] K. Valkeapää, S. Klemetti, E. Cabrera, S. Cano, A. Charalambous, P. Copanitsanou, et al., Knowledge expectations of surgical orthopaedic patients: a European survey, Int. J. Nurs. Pract. 20 (2014) 597-607, doi:http://dx.doi.org/ 10.1111/ijn.12189.

[10] Å. Johansson Stark, B. Ingadottir, S. Salanterä, A. Sigurdardottir, K. Valkeapää, M. Bachrach-Lindström, et al., Fulfilment of hip replacement patients' knowledge expectations, and its relationship with emotional state: a survey in three Nordic countries, Int. J. Nurs. Stud. 51 (2014) 1491-1499, doi:http://dx. doi.org/10.1016/j.ijnurstu.2014.03.006.

[11] S. Rankinen, S. Salanterä, K. Heikkinen, K. Johansson, A. Kaljonen, H. Virtanen, et al., Expectations and received knowledge by surgical patients, Int. J. Qual. Heal. Care 19 (2007) 113-119, doi:http://dx.doi.org/10.1093/intqhc/mzl075.

[12] S. Klemetti, H. Leino-Kilpi, E. Cabrera, P. Copanitsanou, B. Ingadottir, N. Istomina, et al., Difference between received and expected knowledge of patients undergoing knee or hip replacement in seven European countries, Clin. Nurs. Res. 24 (2015) 624-643, doi:http://dx.doi.org/10.1177/ 1054773814549992.

[13] L. Montin, T. Suominen, E. Haaranen, J. Katajisto, J. Lepistö, H. Leino-Kilpi, The changes in health-related quality of life and related factors during the process of total hip arthroplasty, Int. J. Nurs. Pract. 17 (2011) 19-26, doi:http://dx.doi. org/10.1111/j.1440-172X.2010.01901.x.

[14] E.A. Phelan, R.A. Deyo, D.C. Cherkin, J.N. Weinstein, M.A. Ciol, W. Kreuter, et al. Helping patients decide about back surgery: a randomized trial of an interactive video program, Spine (Phila. Pa. 1976) 26 (2001) 206-211, doi: http://dx.doi.org/10.1097/00007632-200101150-00016.

[15] C.Y. Ng, J.N.A. Gibson, An aid to the explanation of surgical risks and complications: the International Spinal Surgery Information Sheet, Spine (Phila. Pa. 1976) 36 (2011) 2333-2345, doi:http://dx.doi.org/10.1097/ BRS.0b013e3182091bbc.

[16] J.D. Lurie, K.F. Spratt, E.A. Blood, T.D. Tosteson, A.N.A. Tosteson, J.N. Weinstein, Effects of viewing an evidence-based video decision aid on patients' treatmen preferences for spine surgery, Spine (Phila. Pa. 1976) 36 (2011) 1501-1504, doi: http://dx.doi.org/10.1097/BRS.0b013e3182055c1e.

[17] M.-R. Bong, H.-A. Park, The development and evaluation of a Web-site for patients undergoing spinal fusion, Stud. Health Technol. Inform. 122 (2006) 826.

[18] A.H. McGregor, A. Henley, T.P. Morris, C.J. Doré, Patients' views on an education booklet following spinal surgery, Eur. Spine J. 21 (2012) 1609-1615, doi:http:// dx.doi.org/10.1007/s00586-012-2242-y.

[19] C. Feste, R.M. Anderson, Empowerment: from philosophy to practice, Patient Educ. Couns. 26 (1995) 139-144, doi:http://dx.doi.org/10.1016/0738-3991(95) 00730-N.

[20] H. Leino-Kilpi, E. Luoto, J. Katajisto, Elements of empowerment and MS patients, J. Neurosci. Nurs. 30 (1998) 116-123, doi:http://dx.doi.org/10.1097/ 01376517-199804000-00005.

[21] K. Heikkinen, H. Leino-Kilpi, A. Hiltunen, K. Johansson, A. Kaljonen, S. Rankinen, et al., Ambulatory orthopaedic surgery patients' knowledge expectations and perceptions of received knowledge, J. Adv. Nurs. 60 (2007) 270-278, doi:http://dx.doi.org/10.1111/j.1365-2648.2007.04408.x.

[22] A.R. Falk Rafael, Advocacy and empowerment: dichotomous or synchronous concepts? Adv. Nurs. Sci. 18 (1995) 25-32.

[23] A.R. Falk-Rafael, Empowerment as a process of evolving consciousness: a model of empowered caring, Adv. Nurs. Sci. 24 (2001) 1-16.

[24] R.M. Anderson, M.M. Funnell, Patient empowerment: myths and misconceptions, Patient Educ. Couns. 79 (2010) 277-282, doi:http://dx.doi. org/10.1016/j.pec.2009.07.025.

[25] H. Leino-Kilpi, K. Johansson, K. Heikkinen, A. Kaljonen, H. Virtanen, S. Salanterä, Patient education and health-related quality of life: surgical hospital patients as a case in point, J. Nurs. Care Qual. 20 (2005) 307-316.

[26] R. Suhonen, H. Leino-Kilpi, Adult surgical patients and the information provided to them by nurses: a literature review, Patient Educ. Couns. 61 (2006) 5-15, doi:http://dx.doi.org/10.1016/j.pec.2005.02.012.

[27] K. Johansson, L. Nuutila, H. Virtanen, J. Katajisto, S. Salanterä, Preoperative education for orthopaedic patients: systematic review, J. Adv. Nurs. 50 (2005) 212-223, doi:http://dx.doi.org/10.1111/j.1365-2648.2005.03381.x.

[28] M. Poskiparta, L. Liimatainen, T. Kettunen, P. Karhila, From nurse-centered health counseling to empowermental health counseling, Patient Educ. Couns. 45 (2001) 69-79.

[29] R.M. Anderson, M.M. Funnell, R. Nwankwo, M. Lou Gillard, M. Oh, J.T. Fitzgerald, Evaluating a problem-based empowerment program for African Americans with diabetes: results of a randomized controlled trial, Ethn. Dis. 15 (2005) 671-678.

[30] K. Heikkinen, L.K. Helena, N. Taina, K. Anne, S. Sanna, A comparison of two educational interventions for the cognitive empowerment of ambulatory orthopaedic surgery patients, Patient Educ. Couns. 73 (2008) 272-279, doi: http://dx.doi.org/10.1016/j.pec.2008.06.015.
[31] J.-S. Lee, Y.-M. Park, K.-Y. Ha, S.-W. Cho, G.-H. Bak, K.-W. Kim, Preoperative anxiety about spinal surgery under general anesthesia, Eur. Spine J. 25 (2016) 698-707, doi:http://dx.doi.org/10.1007/s00586-015-3788-2.

[32] S.-Y. Lin, H.-A. Huang, S.-C. Lin, Y.-T. Huang, K.-Y. Wang, H.-Y. Shi, The effect of an anaesthetic patient information video on perioperative anxiety, Eur. J Anaesthesiol. 33 (2016) 134-139, doi:http://dx.doi.org/10.1097/ EJA.0000000000000307.

[33] M. Sjöling, G. Nordahl, N. Olofsson, K. Asplund, The impact of preoperative information on state anxiety, postoperative pain and satisfaction with pain management, Patient Educ. Couns. 51 (2003) 169-176.

[34] U.F. Trummer, U.O. Mueller, P. Nowak, T. Stidl, J.M. Pelikan, Does physicianpatient communication that aims at empowering patients improve clinical outcome? A case study, Patient Educ. Couns. 61 (2006) 299-306, doi:http://dx. doi.org/10.1016/j.pec.2005.04.009.

[35] K. Johansson, S. Salanterä, J. Katajisto, Empowering orthopaedic patients through preadmission education: results from a clinical study, Patient Educ. Couns. 66 (2007) 84-91, doi:http://dx.doi.org/10.1016/j.pec.2006.10.011.

[36] H. Leino-Kilpi, W. Gröndahl, A. Pekonen, J. Katajisto, R. Suhonen, K. Valkeapää, et al., Knowledge received by hospital patients-a factor connected with the patient-centred quality of nursing care, Int. J. Nurs. Pract. 21 (2015) 689-698, doi:http://dx.doi.org/10.1111/ijn.12277.

[37] J. Hattie, H. Timperley, The power of feedback, Rev. Educ. Res. 77 (2007) 81112.

[38] K.S. Khan, D.A. Davies, J.K. Gupta, Formative self-assessment using multiple true-false questions on the Internet: feedback according to confidence about correct knowledge, Med. Teach. 23 (2001) 158-163, doi:http://dx.doi.org/ $10.1080 / 01421590031075$.

[39] H. Virtanen, H. Leino-Kilpi, S. Salanterä, Empowering discourse in patient education, Patient Educ. Couns. 66 (2007) 140-146, doi:http://dx.doi.org/ 10.1016/j.pec.2006.12.010.

[40] H. Virtanen, H. Leino-Kilpi, K. Leinonen, P. Puukka, J. Wöntsö, S. Salanterä, Nursing student control over using a computer simulation program about empowering discourse, Comput. Inform. Nurs. 31 (2013) 512-522, doi:http:// dx.doi.org/10.1097/01.NCN.0000432119.56581.24.

[41] C.D. Spielberger, R.L. Gorsuch, R.E. Lushene, P.R. Vagg, G.A. Jacobs, Manual for the State-Trait Anxiety Inventory, Mind Garden Inc., Palo Alto, 1983.

[42] T. Treasure, K.D. MacRae, Minimisation is much better than the randomised block design in certain cases, BMJ 318 (1999) 1420.

[43] G.L. Moseley, M.K. Nicholas, P.W. Hodges, A randomized controlled trial of intensive neurophysiology education in chronic low back pain, Clin. J. Pain 20 (2004) 324-330.

[44] T. Kettunen, M. Poskiparta, L. Liimatainen, Empowering counseling - a case study: nurse-patient encounter in a hospital, Health Educ. Res. 16 (2001) 227238, doi:http://dx.doi.org/10.1093/her/16.2.227.

[45] M.R. Lynn, Determination and quantification of content validity, Nurs. Res. 35 (1986) 382-385.

[46] S. Klemetti, I. Kinnunen, T. Suominen, H. Antila, T. Vahlberg, R. Grenman, et al., The effect of preoperative nutritional face-to-face counseling about child's fasting on parental knowledge, preoperative need-for-information, and anxiety, in pediatric ambulatory tonsillectomy, Patient Educ. Couns. 80 (2010) 64-70, doi:http://dx.doi.org/10.1016/j.pec.2009.10.003.

[47] K. Varantola, V. Launis, M. Helin, S.K. Spoof, S. Jäppinen, eds, Responsible Conduct of Research and Procedures for Handling Allegations of Misconduct in Finland, Finnish Advisory Board on Research Integrity, Helsinki, 2013.

[48] A. Pearson, R. Wiechula, A. Court, C. Lockwood, The JBI model of evidencebased healthcare, Int. J. Evid. Based. Healthc. 3 (2005) 207-215, doi:http://dx. doi.org/10.1111/j.1479-6988.2005.00026.x.

[49] C.B. Terwee, S.D.M. Bot, M.R. de Boer, D.A.W.M. van der Windt, D.L. Knol, J. Dekker, et al., Quality criteria were proposed for measurement properties of health status questionnaires, J. Clin. Epidemiol. 60 (2007) 34-42, doi:http://dx. doi.org/10.1016/j.jclinepi.2006.03.012.

50] M. Nordlund, L. Stenberg, H.-M. Lempola, Use of Information Technology, Reasons for Non-use, Age Group 75-89 75-89 - Survey Summary, KAKATE Proj. LăhiVerkko Proj., (2014) http://www.ikateknologia.fi/images/stories/ English/Gallup-koosteEnkku_nettiin.pdf (accessed 29.09.15).

[51] K. Lonka, S. Lindblom-Ylänne, Epistemologies conceptions of learning, and study practices in medicine and psychology, High. Educ. 31 (1996) 5-24.

[52] S.K. Grove, N. Burns, J.R. Gray, The Practice of Nursing Research: Appraisal, Synthesis, and Generation of Evidence, 7th ed., Elsevier Saunders St Louis, 2013.

[53] B. Strömqvist, P. Fritzell, O. Hägg, B. Jönsson, B. Sandén, Swespine: the Swedish spine register the 2012 report, Eur. Spine J. 22 (2013) 953-974, doi:http://dx. doi.org/10.1007/s00586-013-2758-9.

[54] A. Kalenius, Suomalaisten koulutusrakenteen kehitys 1970-2030 [The Development of Finnish Education Structure 1970-2030], The Ministry of Education and Culture, 2014. 